\title{
Safety Index for Evaluation of Two-Lane Rural Highways
}

By:

Salvatore Cafiso

Associate Professor

Department of Civil and Environmental Engineering

University of Catania

Viale Andrea Doria 6, 95125 Catania, Italy

Phone: +390957382213

Fax: $\quad+390957382247$

E-mail:_dcafiso@dica.unict.it

Grazia La Cava

Ph.D., P.Eng.

Department of Civil and Environmental Engineering

University of Catania

Viale Andrea Doria 6, 95125 Catania, Italy

Phone: $\quad+390957382223$

Fax: $\quad+390957382247$

E-mail:_glacava@dica.unict.it

Alfonso Montella

Ph.D., P.Eng., Assistant Professor

University of Naples Federico II

Department of Transportation Engineering "Luigi Tocchetti"

Via Claudio 21, 80125 Naples, Italy

Phone: $\quad+390817683941$

Fax: $\quad+390817683946$

E-mail: alfonso.montella@unina.it

Submission date: 28 July 2006

Words count: $5,411+250 \times 10=7,911$ 


\begin{abstract}
A methodological approach for the safety evaluation of two-lane rural highway segments that uses both analytical procedures referring to alignment design consistency models and safety inspection processes is presented. A safety index (SI) that quantitatively measures the relative safety performance of a road segment is calculated from the procedure. The SI is formulated by combining three components of risk: the exposure of road users to road hazards, the probability of a vehicle being involved in an accident and the resulting consequences should an accident occur.

This systematic and replicable procedure integrates two different, complementary approaches, one based on design consistency evaluations and the other on safety inspections, and makes it possible to effectively address a wide variety of safety issues. A further advantage of the procedure is its applicability on highways where crash data are either not available or are unreliable. Validation of the procedure was carried out on a sample of roads by a comparison of the risk rank obtained using the SI and accident history. The SI was assessed in 30 segments chosen from a sample of two-lane rural highways in Italy and the actual accident situation was obtained with the EB procedure. Spearman's rank-correlation was used to determine the level of agreement between the rankings obtained using the two techniques. The results from the Spearman's rank-correlation analysis validate the SI, indicating that the ranking from the SI scores and the EB estimates agree at the $99.9 \%$ level of significance with a correlation coefficient of 0.87 .
\end{abstract}

Keywords: road safety inspections, design consistency, safety index, ranking criteria, EB procedure. 


\section{INTRODUCTION}

Road safety evaluations on low and medium traffic rural two-lane highways can raise concerns both due to the general deficiency of reliable data on road accidents and to the circumstance that few accident data not always can give enough information on accidents to be prevented. Based on these considerations, a methodological approach for the safety evaluation of two-lane rural highways was defined which uses both analytical procedures referring to alignment design consistency models and the safety inspection process. The research was performed as part of the project "Identification of Hazard Locations and Ranking of Measures to Improve Safety on Local Rural Roads" (Italian acronym IASP), funded by the European Commission (DG TREN) and the Province of Catania (Italy) (1-5).

Many studies show that safety evaluations based on the analysis of alignment design consistency can be effective in identifying hazardous road locations (6-7). The proposed approach makes use of theoretical-experimental models for the evaluation of alignment design consistency. However, the resulting analyses, although effective in addressing alignment inconsistencies, do not highlight all the potential accident contributory factors. Hence, the IASP methodology integrates the results of the models with those deriving from the safety issues evaluation made during the Safety Inspection process.

Road Safety Inspections (RSI) are aimed at identifying potential hazards, which are assessed by measuring risk in relation to those road features that may lead to future accidents, so that remedial treatments may be implemented before accidents happen (8). Safety inspections are recognized as an effective tool and are becoming an accepted practice in many agencies around the world (9-14). Recent researches performed in British Columbia (15) and in Italy (8) have shown that road safety impact assessment based on RSIs can be effective. In order to use safety inspections as part of a quantitative safety evaluation process, the IASP project defined procedures and criteria for identifying and ranking safety issues (2). The ranking criteria take into account the road safety effects of the identified issues. The RSI, carried out according to these procedures, showed that there is a statistically-significant level of agreement (measured through the $\mathrm{k}$ test) between the safety issues evaluations produced by different inspectors, for the majority of the safety issues. A systematic and replicable safety inspection process allows a quantitative safety index (SI) to be assessed, based on the data obtained from the RSI combined with information from theoretical-experimental models.

\section{FORMULATION OF THE SAFETY INDEX}

The safety index (SI) measures the relative safety performance of a road segment. It does not take into account junctions and it refers to two-lane rural highways.

The SI is formulated by combining three components of risk: the exposure of road users to road hazards (Exposure factor), the probability of a vehicle being involved in an accident (Accident Frequency factor) and the resulting consequences should an accident occur (Accident Severity factor).

General formulation of SI is as follows:

SI $=$ Exposure factor $\times$ Accident Frequency factor $\times$ Accident Severity factor 


\section{Exposure Factor}

The Exposure factor measures the exposure of road users to road hazards, and is assessed by equation 2 as follows:

Exposure factor $=\mathrm{L} \times \mathrm{AADT}$

where:

$\mathrm{L}=$ length of the segment under consideration $(\mathrm{km}) ;$

$\mathrm{AADT}=$ average annual daily traffic [(1,000 vehicles per day $)]$.

\section{Accident Frequency Factor}

The Accident Frequency factor depends on the safety features of the segment, which are assessed by two analysis methodologies:

- road safety inspections;

- design consistency evaluations and design standards check.

The Accident Frequency factor is obtained by the formula:

Accident Frequency factor $=\mathrm{RSI}$ AF $\times$ GD AF

where:

RSI AF = Road Safety Inspection Accident Frequency factor;

GD AF $=$ Geometric Design Accident Frequency factor.

\section{Road Safety Inspections}

RSI procedures defined by the IASP research program are aimed at improving the effectiveness and reliability of the methodology (2). Indeed, even though safety evaluations based on inspections are subjective in nature, ranking of safety issues performed in 200 segments by two groups of safety specialists has shown that there is a statistically significant level of agreement among inspectors for the majority of the safety issues (5).

Rankings are carried out using checklists relating to the main safety features that may be consistently present along two-lane rural roads. Checklists are filled in for both directions of the road, with a step of $200 \mathrm{~m}$. Procedures and criteria for identifying and ranking safety issues were defined (see Table 1) (2, 3). Safety issues are ranked as 'high level problem' (score equal to 1), 'low level problem' (score equal to 0.5 ) and 'no problem' (score equal to $0)$.

The following safety issues are assessed using defined criteria: accesses, cross section, delineation, markings, pavement, roadside, sight distance, signs. In order to improve the evaluation of safety issues, each item is divided into more detail (see Table 1). 
TABLE 1 Safety Issues of Road Safety Inspections

\begin{tabular}{|c|c|c|c|}
\hline $\begin{array}{l}\text { Safety } \\
\text { Issue }\end{array}$ & $\begin{array}{l}\text { Detailed } \\
\text { Safety Issue }\end{array}$ & $\begin{array}{l}\text { Main Criteria for Identifying } \\
\text { High Level Problems } \\
\left(\mathrm{S}_{\mathrm{ik}}=1\right) \\
\end{array}$ & $\begin{array}{l}\text { Main Criteria for Identifying } \\
\text { Low Level Problems } \\
\left(\mathrm{S}_{\mathrm{ik}}=0.5\right) \\
\end{array}$ \\
\hline \multirow[t]{2}{*}{ Accesses } & $\begin{array}{l}\text { Dangerousness of } \\
\text { accesses }\end{array}$ & $\begin{array}{l}\text { Location on horizontal curves, on } \\
\text { crests, on sites with poor } \\
\text { visibility, close to intersections }\end{array}$ & Unpaved accesses, narrow accesses \\
\hline & Density of accesses & $\begin{array}{l}\text { Three or more accesses in one } 200 \\
\mathrm{~m} \text { long stretch }\end{array}$ & $\begin{array}{l}\text { One or two accesses in one } 200 \mathrm{~m} \\
\text { long stretch }\end{array}$ \\
\hline $\begin{array}{l}\text { Cross } \\
\text { section }\end{array}$ & $\begin{array}{l}\text { Lane width } \\
\text { Shoulder width }\end{array}$ & $\begin{array}{l}\mathrm{L}<2.75 \mathrm{~m} ; \mathrm{L}>4.50 \mathrm{~m} \\
\text { Width }<0.30 \mathrm{~m}\end{array}$ & $\begin{array}{l}2.75 \leq \mathrm{L}<3.25 \mathrm{~m} ; 3.75<\mathrm{L} \leq 4.50 \mathrm{~m} \\
0.30 \leq \text { Width }<1.00 \mathrm{~m}\end{array}$ \\
\hline \multirow[t]{2}{*}{ Delineation } & Chevrons & $\begin{array}{l}\text { Missing chevrons on severe } \\
\text { curves } \\
\text { Chevron placement or visibility } \\
\text { inadequate to give correct } \\
\text { perception of the curve }\end{array}$ & $\begin{array}{l}\text { Missing chevrons on moderate } \\
\text { curves } \\
\text { Partially obscured chevrons } \\
\text { Low reflective chevrons }\end{array}$ \\
\hline & $\begin{array}{l}\text { Guideposts and barrier } \\
\text { reflectors }\end{array}$ & $\begin{array}{l}\text { Missing guideposts } \\
\text { Missing reflectors on guideposts, } \\
\text { on roadside safety barriers or on } \\
\text { roadside walls }\end{array}$ & $\begin{array}{l}\text { Variable height of reflectors along } \\
\text { the road } \\
\text { Low reflective guideposts } \\
\text { Local discontinuity of guideposts }\end{array}$ \\
\hline \multirow[t]{2}{*}{ Markings } & Edge lines & $\begin{array}{l}\text { Missing edge lines } \\
\text { Very faded edge lines }\end{array}$ & $\begin{array}{l}\text { Slightly faded edge lines } \\
\text { Edge lines partially obscured by the } \\
\text { vegetation }\end{array}$ \\
\hline & Center line & $\begin{array}{l}\text { Missing center line } \\
\text { Very faded center line }\end{array}$ & Slightly faded center line \\
\hline \multirow[t]{2}{*}{ Pavement } & Friction & $\begin{array}{l}\text { Polished aggregate, bleeding, } \\
\text { raveling, low macro-texture }\end{array}$ & $\begin{array}{l}\text { Not defined, friction is ranked as } \\
\text { high level problem or no problem }\end{array}$ \\
\hline & Une & $\begin{array}{l}\text { Potholes, rutting, patches, shoving } \\
\text { on curves or close to intersections }\end{array}$ & $\begin{array}{l}\text { Little shoving, shallow potholes, } \\
\text { rutting, patches on tangents }\end{array}$ \\
\hline \multirow[t]{5}{*}{ Roadside } & Embankments & $\begin{array}{l}\text { Unshielded embankments with } \\
\text { great slope }(\mathrm{h}>3 \mathrm{~m}, \mathrm{i} \geq 2 / 3)\end{array}$ & $\begin{array}{l}\text { Unshielded embankments with } \\
\text { medium slope }(\mathrm{h}>3 \mathrm{~m}, 1 / 3 \leq \mathrm{i}<2 / 3)\end{array}$ \\
\hline & Bridges & Ineffective barriers & $\begin{array}{l}\text { Medium containment barriers if the } \\
\text { bridge overpasses roads or railways }\end{array}$ \\
\hline & $\begin{array}{l}\text { Dangerous terminals } \\
\text { and transitions }\end{array}$ & $\begin{array}{l}\text { No breakaway terminals (fish } \\
\text { tails, buried in the ground, etc.) }\end{array}$ & $\begin{array}{l}\text { Inadequate transition between steel } \\
\text { barriers }\end{array}$ \\
\hline & $\begin{array}{l}\text { Trees, utility poles and } \\
\text { rigid obstacles }\end{array}$ & $\begin{array}{l}\text { High diameter trees or rigid } \\
\text { obstacles located less than } 3 \mathrm{~m} \\
\text { from carriageway }\end{array}$ & $\begin{array}{l}\text { High diameter trees or rigid obstacles } \\
\text { located between } 3 \text { and } 8 \mathrm{~m} \text { from } \\
\text { carriageway }\end{array}$ \\
\hline & Ditches & $\begin{array}{l}\text { Rectangular or trapezoidal ditches } \\
\text { located less than } 3 \mathrm{~m} \text { from } \\
\text { carriageway }\end{array}$ & $\begin{array}{l}\text { Rectangular or trapezoidal ditches } \\
\text { located between } 3 \text { and } 5 \mathrm{~m} \text { from } \\
\text { carriageway }\end{array}$ \\
\hline \multirow[t]{2}{*}{$\begin{array}{l}\text { Sight } \\
\text { distance }\end{array}$} & $\begin{array}{l}\text { Inadequate sight } \\
\text { distance on horizontal } \\
\text { curve }\end{array}$ & $\begin{array}{l}\text { Available sight distance less than } \\
50 \mathrm{~m} \text { caused by continuous } \\
\text { obstructions to visibility inside the } \\
\text { curve }\end{array}$ & $\begin{array}{l}\text { Available sight distance greater than } \\
50 \mathrm{~m} \text { but less than SSD or inadequate } \\
\text { to give the correct road perception }\end{array}$ \\
\hline & $\begin{array}{l}\text { Inadequate sight } \\
\text { distance on vertical } \\
\text { curve }\end{array}$ & $\begin{array}{l}\text { Available sight distance less than } \\
50 \mathrm{~m}\end{array}$ & $\begin{array}{l}\text { Available sight distance greater than } \\
50 \mathrm{~m} \text { but less than SSD or inadequate } \\
\text { to give the correct road perception }\end{array}$ \\
\hline Sign: & $\begin{array}{l}\text { Warning signs, } \\
\text { regulation signs }\end{array}$ & $\begin{array}{l}\text { Missing curve and/or crest } \\
\text { warning sign }\end{array}$ & $\begin{array}{l}\text { Curve and/or crest warning sign } \\
\text { faded or with low visibility }\end{array}$ \\
\hline
\end{tabular}


Using scores assigned to each inspection unit (segment $200 \mathrm{~m}$ long) during the survey, a weighted score of each safety issue $\mathrm{j}\left(\mathrm{WS}_{\mathrm{j}}\right)$, ranging from 0 to 1 , is computed by the formula:

$\mathrm{WS}_{\mathrm{j}}=\frac{1}{2 \times \mathrm{n} \times m_{j}} \times \sum_{i=1}^{m_{j}} \sum_{k=1}^{2 \times n} S_{i k}$

where:

$\mathrm{S}_{\mathrm{ik}}=$ score of the detailed safety issue $\mathrm{i}$ in the inspection unit $\mathrm{k}$;

$\mathrm{n}=$ number of inspection units which form the section under consideration;

$\mathrm{m}_{\mathrm{j}}=$ number of detailed issues associated with the issue $\mathrm{j}$;

$2=$ factor to take both directions into account. formula:

For each safety issue $\mathrm{j}$ the related Accident Frequency factor $\left(\mathrm{AF}_{\mathrm{j}}\right)$ is computed by the

$\mathrm{AF}_{\mathrm{j}}=1+\mathrm{WS}_{\mathrm{j}} \times \Delta \mathrm{AF}_{\mathrm{j}} \times \mathrm{P}_{\mathrm{j}}$

where:

$\Delta \mathrm{AF}_{\mathrm{j}}=$ estimated relative increase in accident risk due to the issue $\mathrm{j}$;

$P_{j}=$ proportion of accidents typologies affected by the issue $\mathrm{j}$.

The cumulative influence of all the safety issues $\mathrm{j}$ is assessed by the RSI Accident Frequency factor, computed as follows:

$\mathrm{RSI} A F=\prod_{\mathrm{j}=1}^{\ell} \mathrm{AF}_{\mathrm{j}}$

where:

$\ell=$ number of safety issues, equal to 8 in the IASP model.

Based on existing literature, the relative increase in accident risk due to each issue was estimated (see Table 2).

TABLE 2 Safety Effects of the Issues

\begin{tabular}{lcc}
\hline Safety Issue & Related Accidents & $\Delta$ AF (\%) \\
\hline Accesses & All & 135 \\
Cross section & Run off the road & $15-100$ \\
& Head-on & f(AADT) \\
& Sideswipe & \\
Delineation & All & 30 \\
Markings & All & 20 \\
Pavement & All & 10 \\
Roadside & Run off the road & 0 \\
Sight distance & All & 50 \\
Signs & All & 20 \\
\hline
\end{tabular}


Many studies have been performed to estimate the safety impact of various types of engineering improvement. Many existing Accident Modification Factors (AMFs) are derived from before-after analysis of actual countermeasure implementation. Indeed, such beforeafter studies, as opposed to cross-sectional/regression-type analysis, will produce the best AMF estimates, but only if conducted properly (16). Unfortunately, many current studies reflect changes in crash experience resulting from improvements at sites that had experienced unusually high accident rates in the before-treatment period. The selection bias inherent in this approach often results in significantly exaggerated AMF estimates due to the phenomenon of regression to the mean. The most accurate AMFs have been developed in rigorous before-after studies that incorporated the current best study design and statistical analysis methods. At this time, the empirical Bayes (EB) methodology represents the best available approach (17-19).

Change in accident risk $\left(\triangle \mathrm{AF}_{\mathrm{j}}\right)$ is related to the Accident Modification Factor $\left(\mathrm{AMF}_{\mathrm{j}}\right)$ of the safety issue by the formula:

$\Delta \mathrm{AF}_{\mathrm{j}}=\mathrm{AMF}_{\mathrm{j}}-1$

Below, explanations of the relative increase in accident risk estimates for each safety issue are briefly reported.

Accesses Direct accesses to roads can significantly increase accidents. The location of access points (e.g., accesses on horizontal curves) can be very dangerous. AMFs that take into account driveway density have been developed (20): they show the dramatic effect of accesses on road safety. The $\triangle \mathrm{AF}$ relative to a high frequency of dangerous accesses (40 accesses $/ \mathrm{km}$ ) is equal to $135 \%$.

Cross section Cross section width affects single vehicle, run-off-the-road and multiple vehicle, head-on, opposite-direction sideswipe and same-direction sideswipe accidents (20, 21 ). The greater the lane and shoulder widths, the fewer the accidents. A bottom value in the lane width exists: too-wide lanes may be counter-productive $(6,22)$. The effect of cross section width is more pronounced for high traffic volumes and is assessed on the basis of the AMFs reported in (20). If AADT is greater than 2,000 vpd, very narrow lanes and shoulders, compared with ideal lanes and shoulders, increase related accident probability by $100 \%$. If AADT is less than $400 \mathrm{vpd}$, the increase in related accident probability is $15 \%$. With intermediate $\mathrm{AADT}$ values, the $\triangle \mathrm{AF}$ varies linearly between these extreme values.

Delineation Daytime delineation of the road can generally be effectively accomplished with pavement markings. Night-time and rainy conditions, however, often require a different approach to provide long-range delineation of the roadway alignment (23). Supplementary delineation is an important safety factor in any condition; on horizontal curves, especially isolated curves with a short radius, it is critical. The chevron alignment sign is an important traffic control device used to warn drivers of the severity of a curve by delineating the alignment of the road around that curve (24). Missing or ineffective chevrons and damaged or missing guideposts or barrier reflectors can lead to an accident risk increase equal to $30 \%$ (12). 
Markings A great deal of literature has investigated the effect of road markings on accidents, showing that their improvement is likely to be cost-effective $(10,12,25-28)$. Relative increase in accident risk was assumed equal to $20 \%$ for missing or ineffective edge lines and center line.

Pavement The pavement factor which has the greatest impact on road safety is friction. The skid resistance of the road surface is an important safety factor, especially when the surface is wet. Several studies (29) show an increase in accident risk when the friction decreases below certain threshold values. Unevenness also affects road safety, although friction effect has been proved by more studies. The $\triangle \mathrm{AF}$ relative to inadequate evenness and friction was selected as equal to $10 \%$.

Roadside The main effect of roadside safety issues is not on accident probability but on accident severity. Therefore, the roadside is computed in the consequence factor of the risk model.

Sight distance Inadequate sight distance on horizontal and vertical curves is a common accident contributory factor. Literature reports widely different values related to the effect of sight distance improvement measures (30-31). Taking into account this variability, the $\Delta \mathrm{AF}$ relative to inadequate sight distance on both horizontal and vertical curves was selected as equal to $50 \%$.

Signs The road signs that have the greatest effect on traffic safety are warning signs (32). They call attention to unexpected conditions and to situations that might not be readily apparent to road users, giving suggestions about safe behavior. Regulatory signs, such as speed limits, can affect road safety by conveying essential information on safe behavior. For missing or ineffective signs, the relative risk factor was assumed as equal to $20 \%$ (33).

\section{Design Consistency Evaluations and Design Standards Check}

A consistent highway design ensures that successive elements are coordinated in such a way as to produce harmonious and homogeneous driver performances along the road. Practice highlights that an alignment with inconsistencies requires drivers to handle speed gradients in order to drive safely on certain alignment elements. On this basis, the importance of identifying inconsistencies on highways and its significant contribution to road safety is emerging as an important feature in highway design.

Design consistency evaluates an overall Safety Module $(6,7,34)$ defining three design classes: poor, fair, good. This Safety Module combines the following three safety criteria (see Table 3):

1. design consistency, related to the difference between the operating speed, represented by the $85^{\text {th }}$ percentile speed $\left(\mathrm{V}_{85}\right)$, and the design speed $\left(\mathrm{V}_{\mathrm{d}}\right)$ of the observed roadway section;

2. operating speed consistency, related to the difference in $\mathrm{V}_{85}$, between two, successive, geometric elements; 
3. driving dynamic consistency, determined by the difference between side friction assumed ( $f_{R A}$, that depends on the design speed) and demanded $\left(f_{R D}\right.$, that depends on the operating speed) on one individual curve.

TABLE 3 Quantitative Ranges for Safety Criteria I to III for Good, Fair, and Poor Design Classes

\begin{tabular}{lccc}
\hline Safety & \multicolumn{3}{c}{ Design Classes } \\
\cline { 2 - 4 } Criterion & \multicolumn{1}{c}{ Good } & Fair & Poor \\
\hline $\mathrm{I}$ & $\left|\mathrm{V}_{85 \mathrm{i}}-\mathrm{V}_{\mathrm{d}}\right| \leq 10 \mathrm{~km} / \mathrm{h}$ & $10 \mathrm{~km} / \mathrm{h}<\left|\mathrm{V}_{85 \mathrm{i}}-\mathrm{V}_{\mathrm{d}}\right| \leq 20 \mathrm{~km} / \mathrm{h}$ & $\left|\mathrm{V}_{85 \mathrm{i}}-\mathrm{V}_{\mathrm{d}}\right|>20 \mathrm{~km} / \mathrm{h}$ \\
$\mathrm{II}$ & $\left|\mathrm{V}_{85 \mathrm{i}}-\mathrm{V}_{85 \mathrm{i}+1}\right| \leq 10 \mathrm{~km} / \mathrm{h}$ & $10 \mathrm{~km} / \mathrm{h}<\left|\mathrm{V}_{85 \mathrm{i}}-\mathrm{V}_{85 \mathrm{i}+1}\right| \leq 20 \mathrm{~km} / \mathrm{h}$ & $\left|\mathrm{V}_{85 \mathrm{i}}-\mathrm{V}_{85 i+1}\right|>20 \mathrm{~km} / \mathrm{h}$ \\
$\mathrm{III}$ & $\mathrm{f}_{\mathrm{RA}}-\mathrm{f}_{\mathrm{RD}} \geq+0.01$ & $-0.04 \leq \mathrm{f}_{\mathrm{RA}}-\mathrm{f}_{\mathrm{RD}}<+0.01$ & $\mathrm{f}_{\mathrm{RA}}-\mathrm{f}_{\mathrm{RD}}<-0.04$ \\
\hline $\mathrm{f}_{\mathrm{RA}}=0.6 \times 0.925 \times\left(0.59-4.85 \times 10^{-3} \times \mathrm{V}_{\mathrm{d}}+1.51 \times 10^{-5} \times \mathrm{V}_{\mathrm{d}}{ }^{2}\right)$ &
\end{tabular}

In order to evaluate the Safety Module, good design is classified by the weighting factor of " +1 ", fair design is described by the factor " 0 " and for poor design the factor " -1 " is used. Summing up the weighting factors for the individual safety criteria, the calculated, average value $x$ represents an evaluation for the safety module as shown in the following: if $x \geq 0.5$ design class is good; if $-0.5<x<0.5$ design class is fair; if $x \leq-0.5$ design class is poor.

Safety criteria evaluation is strictly related to the operating-speed profile. Operating speed can be evaluated using experimental, regression models. Considering that driver behavior and operating speed is influenced by national and environmental factors (6), as part of the research project two experimental regression models were developed for local two-lane rural highways:

$$
\begin{aligned}
& \mathrm{V}_{85}=99.31-0.51 \times \mathrm{CD} \quad \text { (flat environment) } \\
& \mathrm{V}_{85}=82.76-0.45 \times \mathrm{CD} \quad \text { (mountain environment) }
\end{aligned}
$$

where:

$$
\begin{aligned}
\mathrm{CD} & =\frac{360 \times 100}{2 \times \pi \times R}=\text { curvature degree }(\% / 100 \mathrm{~m}) \\
\mathrm{R} & =\text { radius of the curve }(\mathrm{m}) .
\end{aligned}
$$

Regression models were obtained from a survey of actual vehicle operating speeds. The measurements were carried out with a dual-beam laser instrument located transversely across the road. In order to achieve a precision of $1.5 \mathrm{~km} / \mathrm{h}$ in the estimation of the average speed, at a confidence level of $95 \%$ for each section, at least three hundred "isolated" vehicles were measured in good weather and daylight conditions. The measurements were carried out at the midpoint of the curves and at the midpoint of the long tangent between curves.

The Safety Module was used to check the consistency of curves. With regard to the safety concerns related to long or short tangents, two design standards checks were carried out according to the criteria defined in the Italian Standards (35): 1) maximum length of tangents $\left.\left(\mathrm{TL}_{\max }\right) ; 2\right)$ minimum length of tangents $\left(\mathrm{TL}_{\min }\right)$. In order to avoid fatigue and glare from oncoming headlights during night driving, standards require a maximum length of tangents equal to 22 times the speed design $(\mathrm{km} / \mathrm{h})$ of the stretch under analysis. In order to 
perceive the straight element as a tangent, standards suggest a minimum tangent length that depends on the design speed $\left(V_{d}=60 \mathrm{~km} / \mathrm{h}, T L_{\min }=50 \mathrm{~m} ; \mathrm{V}_{\mathrm{d}}=80 \mathrm{~km} / \mathrm{h}, \mathrm{TL}_{\min }=90 \mathrm{~m} ; \mathrm{V}_{\mathrm{d}}=\right.$ $100 \mathrm{~km} / \mathrm{h}, \mathrm{TL}_{\min }=150 \mathrm{~m}$ ).

The Geometric Design Accident Frequency factor (GD AF) is assessed by the formula:

$\mathrm{GD} \mathrm{AF}=1+\mathrm{WS}_{\mathrm{GD}} \times \Delta \mathrm{AF}_{\mathrm{GD}} \times \mathrm{P}_{\mathrm{GD}}$

where:

$\mathrm{WS}_{\mathrm{GD}}=$ weighted score of the safety issue GD;

$\Delta \mathrm{AF}_{\mathrm{GD}}=$ estimated relative increase in accident risk due to the issue GD;

$\mathrm{P}_{\mathrm{GD}}=$ proportion of accidents affected by the issue GD.

For a section of $v$ geometrical elements, $\mathrm{WS}_{\mathrm{GD}}$ is computed through a weighted mean of $\mathrm{GDS}_{\ell}$ :

$$
\mathrm{WS}_{\mathrm{GD}}=\frac{\sum_{\ell=1}^{v} G D S_{\ell} \times L_{\ell}}{\sum_{\ell=1}^{v} L_{\ell}}
$$

where:

$v=$ number of geometrical elements that form the section under consideration;

$\mathrm{L}_{\ell}=$ length of the geometrical element $\ell$;

$\operatorname{GDS}_{\ell}=$ Geometric Design Score of element $\ell$.

Each $\mathrm{GDS}_{\ell}$ (ranging from 0 to 1 ) was estimated (Table 4) by analyzing the increase of the accident rate with respect to:

- poor, fair and good Design Class for the curved elements;

- a check, in terms of minimum or maximum length, which failed Italian design standards (35) for tangents.

TABLE 4 Geometric Design Scores $\left(\right.$ GDS $\left._{\ell}\right)$

\begin{tabular}{llll|l}
\hline Curved Elements & Tangents & Related Accidents \\
\hline Good & 0.2 & Overall Standards Check & 0.0 & Run off the road \\
Fair & 0.5 & Minimum Length & 0.1 & Partially $(50 \%):$ \\
Poor & 1.0 & Maximum length & 0.1 & Head-on \\
& & & Same direction and opposite direction sideswipe \\
\hline
\end{tabular}

The state of the art (7) indicates an increase in accident risk on poor curved segments as compared to tangents $\left(\triangle \mathrm{AF}_{\mathrm{DCS}}\right)$ equal to $700 \%$. 


\section{Accident Severity Factor}

Accident Severity is intended as a measure of the ratio between the number of severe accidents (injury or fatal) and the total number of accidents. Two factors were considered significant:

1) operating speed;

2) roadside hazard.

The Accident Severity factor for the segment is computed with the following formula:

Accident Severity factor $=\left(\frac{\mathrm{V}_{85}}{\mathrm{~V}_{\text {base }}}\right) \times \mathrm{RSI} \mathrm{AS}_{\text {roadside }}$

where:

$$
\begin{aligned}
\mathrm{V}_{85}= & \text { average } 85^{\text {th }} \text { percentile of speed along the segment (weighted to element } \\
& \text { length); } \\
\mathrm{V}_{\text {base }}= & \text { base operating speed for two-lane, local, rural highways (assumed equal to } \\
& \text { the legal speed limit of } 90 \mathrm{~km} / \mathrm{h} \text { ); }
\end{aligned}
$$

Road Safety Inspection Accident Severity factor of the roadside safety issue (RSI $\mathrm{AS}_{\text {roadside }}$ is equal to:

RSI $\mathrm{AS}_{\text {roadside }}=1+\mathrm{WS}_{\text {roadside }} \times \mathrm{P}_{\text {roadside }} \times \Delta \mathrm{AS}_{\text {roadside }}$

where:

$\mathrm{WS}_{\text {roadside }}=$ weighted score of the roadside safety issue;

$\mathrm{P}_{\text {roadside }}=$ proportion of accidents related to the roadside issue, equal to the proportion of run off the road accidents;

$\Delta \mathrm{AS}_{\text {roadside }}=$ estimated relative increase in accident severity due to the issue $\mathrm{j}$. This value was assumed equal to 2 considering the maximum increase in proportion of injury accidents due to roadside hazard $(29,36)$.

Considering that RSI $\mathrm{AS}_{\text {roadside }}$ evaluates roadside items including embankments, bridges, dangerous barrier terminals and transitions, trees, utility poles and rigid obstacles and ditches, a weighted mean of the roadside issue ( $\left.\mathrm{WS}_{\text {roadside }}\right)$ is computed as follows:

$W S_{\text {roadside }}=\frac{\sum_{k=1}^{2 \times n} \max _{i}\left(\text { Score }_{i k} \times \text { Weight }_{i}\right)}{2 \times n \times 5}$

where:

Score $_{\mathrm{ik}}=$ score of the roadside safety items $\mathrm{i}$ in the inspection units $\mathrm{k}(0,0.5$ or 1$)$;

Weight $_{\mathrm{i}}=$ relative weight of the roadside safety item i (see Table 5). 
TABLE 5 Relative Weights of the Roadside Safety Items

\begin{tabular}{lc}
\hline Detailed Safety Issue & Relative Weight \\
\hline Embankments & 3 \\
Bridges & 5 \\
Dangerous terminals and transitions & 2 \\
Trees, utility poles and rigid obstacles & 2 \\
Ditches & 1 \\
\hline
\end{tabular}

Relative increase in accident severity was calculated by using the AASHTO severity indices (36). In relation to design speed, which has been selected as equal to $90 \mathrm{~km} / \mathrm{h}$, severity indices for each roadside feature define the probability of injuries and fatalities, in the case of an accident. Based on accident severities corresponding to high level problems (see Table 1), the different weights of the roadside issues shown in Table 5 were established.

An example real-world application of the procedure is presented in Table 6.

TABLE 6 Example Real-World Application of Procedure (Road SP4II, Section 1)

\begin{tabular}{|c|c|c|c|c|c|c|c|}
\hline $\begin{array}{l}\mathrm{L}(\mathrm{km}) \\
\text { AADT }[(1,000 \text { vehicles per day })] \\
\text { Exposure factor }=\mathbf{L} \times \mathbf{A A D T}\end{array}$ & & & & $\begin{array}{c}3.463 \\
4.10 \\
\mathbf{1 4 . 1 9 7} \\
\end{array}$ & & & \\
\hline & Accesses & $\begin{array}{l}\text { Cross } \\
\text { Section }\end{array}$ & Delineation & Markings & Pavement & $\begin{array}{l}\text { Sight } \\
\text { Distance }\end{array}$ & Signs \\
\hline $\mathrm{WS}_{\mathrm{j}}$ & 0.287 & 0.147 & 0.618 & 1.000 & 0.037 & 0.066 & 0.015 \\
\hline$\Delta \mathrm{AF}_{\mathrm{j}}$ & 1.350 & 1.000 & 0.300 & 0.200 & 0.100 & 0.500 & 0.200 \\
\hline$P_{j}$ & 1.000 & 0.600 & 1.000 & 1.000 & 1.000 & 1.000 & 1.000 \\
\hline$A F_{j}=1+W_{j} \times \Delta A_{j} \times P_{j}$ & 1.387 & 1.088 & 1.185 & 1.200 & 1.004 & 1.033 & 1.003 \\
\hline $\mathrm{RSIAF}=\prod \mathrm{AF}_{\mathrm{j}}$ & & & & 2.233 & & & \\
\hline $\mathrm{WS}_{\mathrm{GD}}$ & & & & 0.064 & & & \\
\hline$\Delta \mathrm{AF}_{\mathrm{GD}}$ & & & & 7.000 & & & \\
\hline $\mathrm{P}_{\mathrm{GD}}$ & & & & 0.450 & & & \\
\hline $\mathrm{GDAF}=1+\mathrm{WS}_{\mathrm{GD}} \times \Delta \mathrm{AF}_{\mathrm{GD}} \times \mathrm{P}_{\mathrm{GD}}$ & & & & 1.202 & & & \\
\hline $\begin{array}{l}\text { Accident Frequency factor }= \\
\text { RSI AF } \times \text { GD AF }\end{array}$ & & & & 2.683 & & & \\
\hline $\mathrm{V}_{85}(\mathrm{~km} / \mathrm{h})$ & & & & 76.94 & & & \\
\hline $\mathrm{V}_{\text {base }}(\mathrm{km} / \mathrm{h})$ & & & & 90 & & & \\
\hline $\mathrm{WS}_{\text {roadside }}$ & & & & 0.253 & & & \\
\hline $\mathrm{P}_{\text {roadside }}$ & & & & 0.300 & & & \\
\hline$\Delta \mathrm{AS}_{\text {roadside }}$ & & & & 2.000 & & & \\
\hline $\begin{array}{l}\text { RSIAS }_{\text {roadside }}= \\
1+\mathrm{WS}_{\text {roadside }} \times \mathrm{P}_{\text {roadside }} \times \Delta \mathrm{AS}_{\text {roadside }}\end{array}$ & & & & 1.152 & & & \\
\hline $\begin{array}{l}\text { Accident Severity factor }= \\
\mathbf{V}_{\mathbf{8 5}} / \mathbf{V}_{\text {base }} \times \text { RSI } \mathbf{A S}_{\text {roadside }}\end{array}$ & & & & 0.985 & & & \\
\hline $\begin{array}{l}\text { SI }=\text { Exposure } \times \text { Accident } \\
\text { Frequency } \times \text { Accident Severity }\end{array}$ & & & & 37.505 & & & \\
\hline
\end{tabular}




\section{VALIDATION OF PROCEDURE}

In view of the complexity of the above-mentioned procedure, its validity was evaluated carrying out a pilot study.

\section{Road Sample and Segmentation}

A sample of about $100 \mathrm{~km}$ of two-lane, local, rural highways, located in the Province of Catania (Italy) was used in order to apply and validate the procedure. A segmentation into homogeneous sections was carried out on the basis of the geometric alignment characteristics and traffic flow volumes. Thirty homogeneous segments were obtained.

\section{EB Estimates}

A model that predicts road segment accident frequency, using the segment length and the AADT volume as explanatory variables, was developed with the data reported in Table 7. Generalized linear modeling techniques (GLIM) were used to fit the model, and a negative binomial distribution error structure was assumed. Many studies $(37,38)$ have demonstrated the inappropriateness of conventional linear regression in modeling discrete, non-negative, rare events such as traffic accident occurrence, due to the non-linear relationship with traffic volume and road length. GLIM has the advantage of overcoming these shortcomings associated with conventional linear regression. The regression analyses were performed by use of the GenStat 7.2 software package.

The model form is as follows:

$$
\hat{E}(Y)=e^{a_{0}} \times L^{a_{1}} \times A A D T^{a_{2}}
$$

$$
\begin{aligned}
& \text { where: } \\
& \begin{aligned}
\hat{E}(\mathrm{Y}) & =\text { predicted accident frequency (in } 5 \text {-year period) } \\
\mathrm{L} & =\text { segment length }(\mathrm{km}) \\
\mathrm{AADT} & =\text { average annual daily traffic (vehicles per day); } \\
\mathrm{a}_{0}, \mathrm{a}_{1}, \mathrm{a}_{2} & =\text { model parameters. }
\end{aligned}
\end{aligned}
$$

The model parameters and the indicators for the model significance are listed in Table 7. The reported indicators are the t-ratio for the model parameters, the $\kappa$ value (the negative binomial parameter), the scaled deviance (SD), the Pearson $\chi^{2}$ statistic and the log likelihood. The formulation of the SD (for a negative binomial distribution) and of the Pearson $\chi^{2}$ statistic are shown in equations 16 and 17. For a well-fitted model, both the scaled deviance and the Pearson $\chi^{2}$ should be significant compared with the critical value obtained from the $\chi^{2}$ distribution for the given degrees of freedom and level of confidence.

$$
S D=2 \sum_{i=1}^{n}\left[y i \ln \left(\frac{y i}{\hat{E}(y i)}\right)-(y i+k) \ln \left(\frac{y i+k}{\hat{E}(y i)+k}\right)\right]
$$


where:

$\mathrm{SD}=$ scaled deviance;

$\mathrm{y}_{\mathrm{i}}=$ observed number of accidents in the segment $\mathrm{i}$;

$\hat{E}\left(\mathrm{y}_{\mathrm{i}}\right)=$ predicted number of accidents in the segment $\mathrm{i}$;

$\mathrm{k}=$ the negative binomial parameter.

Pearson $\chi^{2}=\sum_{i=1}^{n} \frac{[y i-\hat{E}(y i)]^{2}}{\operatorname{Var}(y i)}$

where:

$\operatorname{Var}\left(\mathrm{y}_{\mathrm{i}}\right)=$ variance of the observed accidents.

TABLE 7 Model Parameters and Indicators for Model Goodness of Fit

\begin{tabular}{llrrrrrrrr}
\hline Df & Parameter & Estimate & t-ratio & $\mathbf{t}_{\mathbf{0 . 1 0 , 2 7}}$ & $\mathbf{k}$ & SD & Pearson $\chi^{2}$ & $\chi^{2}{ }_{\mathbf{0 . 1 0 , 2 7}}$ & Log Likelihood \\
\hline \multirow{2}{*}{27} & $\mathrm{a}_{0}$ & -5.861 & -2.48 & & & & & & \\
& $\mathrm{a}_{1}$ & 0.601 & 1.85 & 1.70 & 3.56 & 34.09 & 26.44 & 36.74 & -18.84 \\
& $\mathrm{a}_{2}$ & 0.747 & 2.59 & & & & & & \\
\hline
\end{tabular}

These measures indicate that the prediction model has a relatively good fit and the values that are calculated for the t-ratios for all independent variables are significant.

The collision estimates were then subjected to an Empirical Bayes refinement technique (EB) to correct for regression-to-mean bias and to obtain a better estimate of the expected accident frequency (see Table 8).

EB was produced as follows:

$E B=\left(\frac{\hat{E}(Y)}{k+\hat{E}(Y)}\right) \times(k+$ count $)$

where:

$\mathrm{EB}=$ empirical Bayes estimate of the accident frequency;

count $=$ observed accident frequency. 
TABLE 8 Accident History and EB Estimates

\begin{tabular}{|c|c|c|c|c|c|c|}
\hline Section & $\begin{array}{l}\text { Road } \\
\text { Name }\end{array}$ & $\begin{array}{l}\text { Length } \\
(\mathrm{km})\end{array}$ & $\begin{array}{l}\text { AADT } \\
\text { (veh/day) }\end{array}$ & $\begin{array}{l}\text { Observed } \\
\text { Injury } \\
\text { Accidents }\end{array}$ & $\begin{array}{l}\text { Model } \\
\text { Predicted } \\
\text { Accidents } \\
\end{array}$ & $\begin{array}{l}\text { EB } \\
\text { Estimate }\end{array}$ \\
\hline 1 & SP 4II & 3.463 & 4100 & 5 & 3.01 & 3.92 \\
\hline 2 & SP 4II & 2.782 & 4100 & 2 & 2.64 & 2.37 \\
\hline 3 & SP 4II & 0.639 & 4100 & 3 & 1.09 & 1.54 \\
\hline 4 & SP 4II & 2.740 & 5200 & 5 & 3.13 & 4.00 \\
\hline 5 & SP 57 & 4.505 & 1800 & 5 & 1.91 & 2.99 \\
\hline 6 & SP 57 & 1.399 & 1800 & 0 & 0.94 & 0.75 \\
\hline 7 & SP 69II & 3.084 & 5500 & 1 & 3.50 & 2.26 \\
\hline 8 & SP 69II & 6.425 & 1800 & 5 & 2.36 & 3.41 \\
\hline 9 & SP 69II & 3.115 & 1800 & 3 & 1.53 & 1.97 \\
\hline 10 & SP 69II & 5.328 & 600 & 1 & 0.93 & 0.94 \\
\hline 11 & SP 69II & 1.038 & 600 & 0 & 0.35 & 0.32 \\
\hline 12 & SP 69II & 1.456 & 600 & 0 & 0.43 & 0.38 \\
\hline 13 & SP94 & 5.628 & 900 & 2 & 1.30 & 1.49 \\
\hline 14 & SP94 & 7.636 & 900 & 0 & 1.56 & 1.09 \\
\hline 15 & SP94 & 1.817 & 900 & 1 & 0.66 & 0.71 \\
\hline 16 & SP94 & 2.988 & 900 & 0 & 0.89 & 0.71 \\
\hline 17 & SP104 & 6.854 & 1200 & 1 & 1.81 & 1.54 \\
\hline 18 & SP104 & 2.409 & 1200 & 0 & 0.97 & 0.76 \\
\hline 19 & SP104 & 2.220 & 1200 & 0 & 0.92 & 0.73 \\
\hline 20 & SP104 & 2.874 & 2900 & 0 & 2.08 & 1.31 \\
\hline 21 & SP104 & 2.094 & 2900 & 4 & 1.72 & 2.46 \\
\hline 22 & SP231 & 3.887 & 3500 & 1 & 2.87 & 2.04 \\
\hline 23 & $\mathrm{SC} 4$ & 1.175 & 4500 & 2 & 1.69 & 1.79 \\
\hline 24 & $\mathrm{SC} 4$ & 1.814 & 4000 & 0 & 2.01 & 1.28 \\
\hline 25 & $\mathrm{SC} 4$ & 2.165 & 4000 & 1 & 2.23 & 1.76 \\
\hline 26 & $\mathrm{SC} 4$ & 1.146 & 4000 & 0 & 1.52 & 1.07 \\
\hline 27 & SP 28II & 1.260 & 1100 & 2 & 0.61 & 0.82 \\
\hline 28 & SP 28II & 3.347 & 1100 & 2 & 1.10 & 1.32 \\
\hline 29 & SP 28II & 2.580 & 1100 & 1 & 0.94 & 0.96 \\
\hline 30 & SP 28II & 5.273 & 1100 & 1 & 1.45 & 1.32 \\
\hline
\end{tabular}




\section{Comparison of SI Scores and EB Estimates}

To test the procedure, comparisons were carried out between SI scores and EB safety estimates (see Table 9). The correlation between SI values and EB safety estimates is highly significant $(\mathrm{t}=9.64, \mathrm{p}$-value $<0.001)$, with $77 \%$ of the variation in the estimated number of accidents explained by the SI value (see Figure 1). This means that the relationship between EB estimates and SI scores had less than $0.1 \%$ chance of occurring by accident. Comparisons between SI/L scores and EB/L safety estimates give similar results. The correlation between $\mathrm{EB} / \mathrm{L}$ safety estimates and SI/L values is highly significant $(\mathrm{t}=9.05$, $\mathrm{p}$-value $<0.001)$, with $75 \%$ of the variation in the estimated number of accidents per kilometer explained by the $\mathrm{SI} / \mathrm{L}$ value.

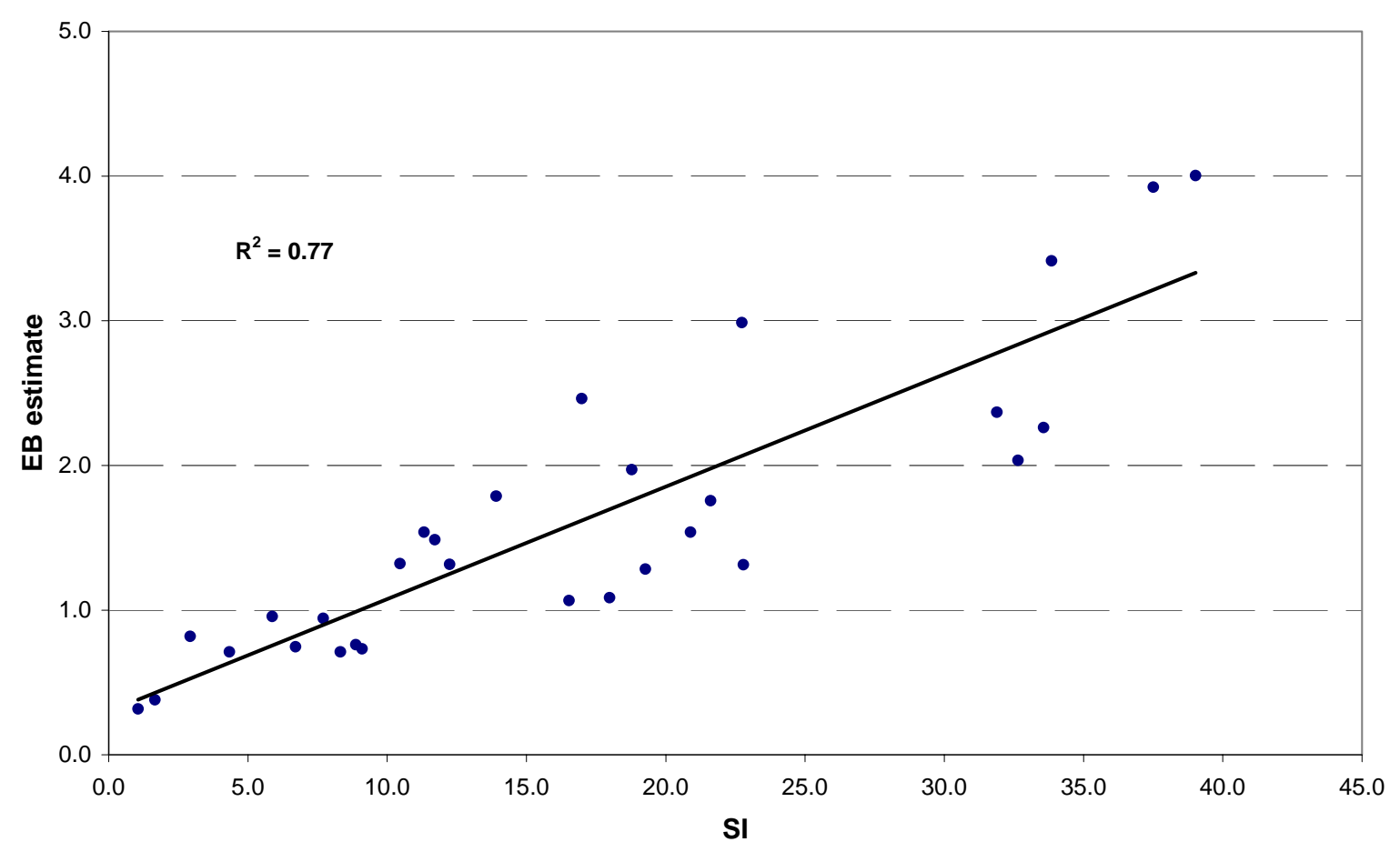

FIGURE 1 Correlation between SI scores and EB safety estimates.

To test the procedure further, a comparison was made of the rankings obtained by the SI and by the EB technique. Indeed, the main target of the procedure is to define management priorities with respect to road safety. Spearman's rank-correlation was used to determine the level of agreement between the rankings obtained using the two techniques. The Spearman's rank-correlation coefficient is a measure of association between the rankings of two variables measured on $\mathrm{N}$ individuals. To calculate the Spearman's rank-correlation coefficient, it is necessary to segment the data sets and then rank the paired data sets in ascending or descending order. The Spearman's rank-correlation coefficient is often used as a nonparametric alternative to a traditional coefficient of correlation and can be applied under general conditions. An advantage of the method is that when testing for correlation between two sets of data, it is not necessary to make assumptions about the nature of the populations sampled. The correlation coefficient is calculated from the two vectors of ranks for the 
samples: let $\{\mathrm{Xi} ; \mathrm{i}=1 \ldots \mathrm{n}\}$ and $\{\mathrm{Yi} ; \mathrm{i}=1 \ldots \mathrm{n}\}$ be the vectors of ranks for sample 1 and sample 2 respectively, then it results:

$\rho_{s}=1-\frac{6 \times \sum_{i=1}^{n} d_{i}^{2}}{n \times\left(n^{2}-1\right)}$

where:

$\rho_{\mathrm{s}}=$ Spearman's rank-correlation coefficient;

$\mathrm{d}_{\mathrm{i}}=$ differences between ranks;

$\mathrm{n}=$ number of paired sets.

TABLE 9 Comparison Between Ranking Criteria

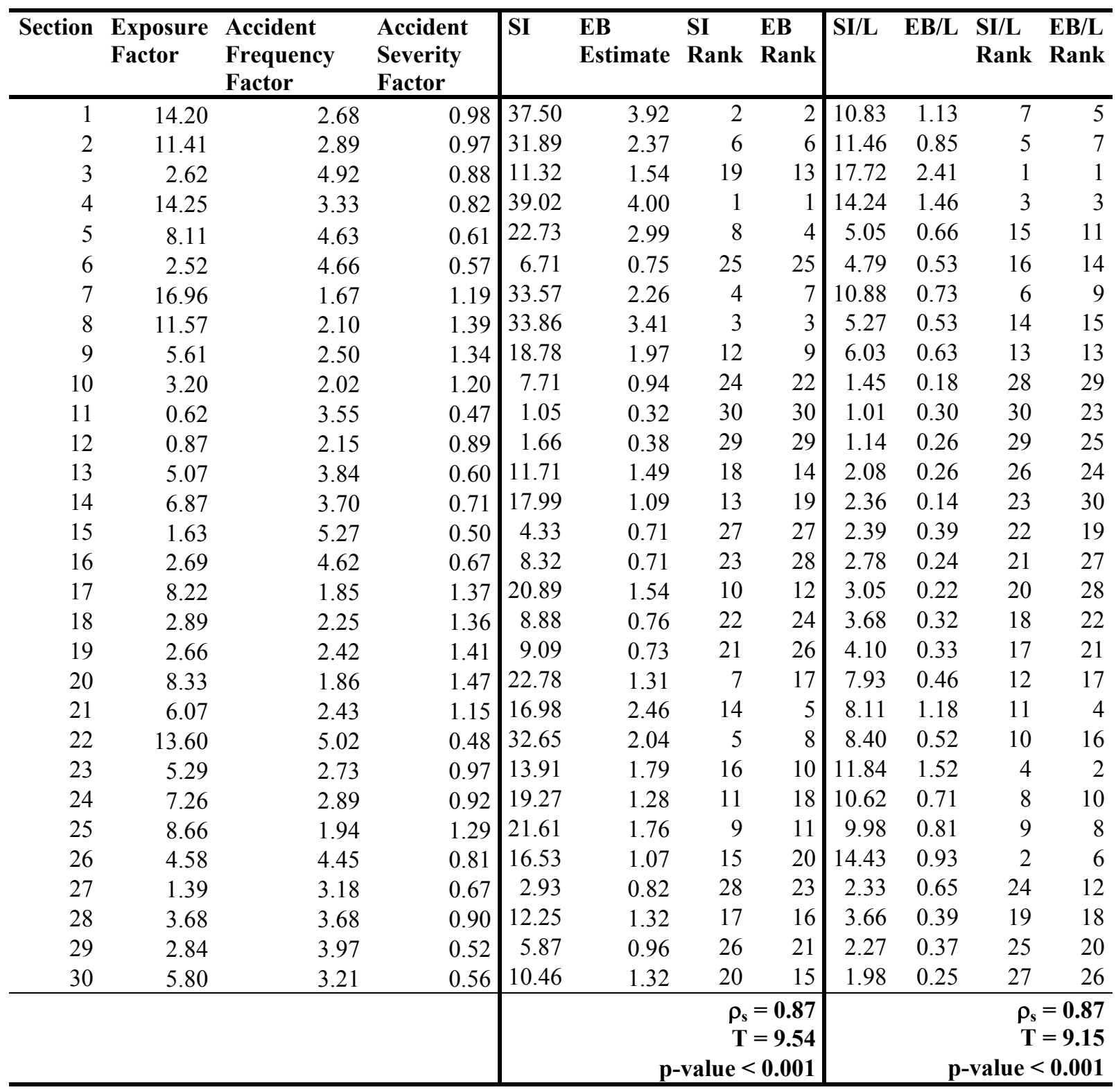


A score of 1.0 represents perfect correlation and a score of zero indicates no correlation. The t-approximation for this statistic, $\mathrm{T}$, is valid for samples of size 8 upwards, and is calculated by:

$$
T=\rho_{s} \times \sqrt{\frac{n-2}{1-\rho_{s}^{2}}}
$$

It has approximately a t-distribution with $\mathrm{n}-2$ degrees of freedom, and can be used for a test of the null hypothesis of independence between samples.

The results from the Spearman's rank-correlation analysis (see Table 8) provide further validation for the SI indicating that the ranking from the SI and the EB estimate agree at the $99.9 \%$ level of significance with a correlation coefficient of 0.87 . The same level of agreement is obtained if rankings from $\mathrm{SI} / \mathrm{L}$ and from $\mathrm{EB} / \mathrm{L}$ are compared.

\section{CONCLUSIONS}

The procedure integrates two different approaches, one based on design consistency evaluation and the other on safety inspections, and makes it possible to effectively address a wide variety of safety issues.

Validation of the safety evaluation procedure was carried out by comparing the results with the accident EB estimates. The SI was assessed in 30 segments of two-lane rural highways in Italy. An accident predictive model was calibrated for the same road network and the EB refinement technique was used to obtain a better estimate of the expected accident frequency. The correlation between SI values and EB safety estimates is highly significant $(\mathrm{t}$ $=9.64$, p-value $<0.001$ ), with $77 \%$ of the variation in the estimated number of accidents explained by the SI value. This means that the relationship between EB estimates and SI scores had less than $0.1 \%$ chance of occurring by accident. Comparisons between SI/L scores and EB/L safety estimates give similar results. Moreover, Spearman's rank-correlation was used to determine the level of agreement between the rankings obtained by the two techniques. The results from the Spearman's rank-correlation analysis provide further validation for the SI indicating that the ranking from the SI and the EB estimate agree at the $99.9 \%$ level of significance with a correlation coefficient of 0.87 . The same level of agreement is obtained if rankings from SI/L and from $\mathrm{EB} / \mathrm{L}$ are compared. These results show that ranking of segments gives comparable results in terms of SI or accident frequency.

The SI can be assessed whether accident data are available or not. If accident data are available and are of good quality, the SI can be effectively used in conjunction with accident frequency as ranking criteria. If accident data are not available or are unreliable, the SI can be used as a proxy for accident data and becomes the only ranking criteria. The SI has two, main applications. High-risk segments, where safety measures that can reduce accident frequency and/or severity already exist, can be identified and ranked by the SI score. Specific safety issues, that give more contribution to unsafety, are pointed out by the Accident Frequency factor and the Accident Severity factor in order to give indications regarding more appropriate mass-action programs. 


\section{REFERENCES}

1. Cafiso, S., G. La Cava, A. Montella, and M. Pernetti. A Methodological Approach for the Safety Evaluation of Minor Two-Lane Rural Roads. In: Proceedings of the Conference European Road Federation - 1st European Road Congress, Lisbon, Portugal, 2004.

2. Cafiso, S., G. La Cava, S. Leonardi, A. Montella, and G. Pappalardo. Operative Procedures for Road Safety Inspections. In: Proceedings of the Conference Road Safety on Four Continents, Varsaw, Poland, 2005.

3. Cafiso, S., G. La Cava, S. Leonardi, A. Montella, and G. Pappalardo. The Safety Inspection Operative Manual. Annex of Mid Term Research Report, European Union DG TREN Project-03-ST-S07.31286, Catania, Italy, 2006.

4. Cafiso, S., A. Di Graziano, G. La Cava, S. Leonardi, A. Montella, G. Pappalardo, and S. Taormina, Identification of Hazard Location and Ranking of Measures to Improve Safety on Local Rural Roads (IASP). Mid Term Research Report, European Union DG TREN Project -03-ST-S07.31286, Catania, Italy, 2006.

5. Cafiso, S., G. La Cava, A. Montella, and G. Pappalardo. A Procedure to Improve Safety Inspections Effectiveness and Reliability on Rural Two-Lane Highways. The Baltic Journal of Road and Bridge Engineering, Volume 1, No.3, 2006, pp. 143-150.

6. Lamm, R., B. Psarianos, T. Mailaender, E.M. Choueiri, R.Heger, and R. Steyer. Highway Design and Traffic Safety Engineering Handbook. McGraw-Hill, New York, N.Y., 1999.

7. Lamm, R., B. Psarianos, and S. Cafiso. Safety Evaluation Process of Two-Lane Roads. A 10-Year Review. In Transportation Research Record: Journal of the Transportation Research Board, No. 1796, TRB, National Research Council, Washington, D.C., 2002, pp. 51-59.

8. Montella, A. Safety Reviews of Existing Roads: Quantitative Safety Assessment Methodology. In Transportation Research Record: Journal of the Transportation Research Board, No. 1922, TRB, National Research Council, Washington, D.C., 2005, pp. 62-72.

9. PIARC, World Road Association, Technical Committee on Road Safety C13. Road Safety Manual. 2004.

10. Transportation Association of Canada. The Canadian Guide to In-Service Road Safety Reviews. Ottawa, Canada, 2004.

11. Wilson, E.M., and M. Lipinsky. Practical Safety Tool for Local Low-Volume Rural Roads: The Road Safety Audit Review. In Transportation Research Record: Journal of the Transportation Research Board, No. 1819, TRB, National Research Council, Washington, D.C., 2003, pp. 225-230.

12. Transfund New Zealand. Safety Audits of Existing Roads: Developing a Less Subjective Assessment. Transfund Report OG/0306/24S, Wellington, New Zealand, 2003.

13. European Union Road Federation. Guidelines to Black Spot Management Identification \& Handling. Brussels, Belgium, 2002.

14. Montella, A., and S. Proctor. Safety Review of the Existing Roads. In: Proceedings of the Conference SORIC'02 - Safety on Roads An International Second Conference, Bahrain, 2002. 
15. De Leur, P., and T. Sayed. Development of a Road Safety Risk Index. In Transportation Research Record: Journal of the Transportation Research Board, No. 1784, TRB, National Research Council, Washington, D.C., 2002, pp. 33-42.

16. Transportation Research Board. Crash Reduction Factors for Traffic Engineering And Intelligent Transportation System (ITS) Improvements: State-of-Knowledge Report. Publication NCHRP Research Results Digest 299, 2005.

17. Hauer, E. Observational Before-After Studies in Road Safety: Estimating the Effect of Highway and Traffic Engineering Measures on Road Safety. Pergamon Press, Elsevier Science, Ltd, Oxford, UK, 1997.

18. Hauer, E., D.W. Harwood, F.M. Council, and M.S. Griffith. Estimating Safety by the Empirical Bayes Method: A Tutorial. In Transportation Research Record: Journal of the Transportation Research Board, No. 1784, TRB, National Research Council, Washington, D.C., 2002, pp. 126-131.

19. Persaud, B., and C. Lyon. Validity of Results from Empirical Bayes Observational Before-After Studies. In: Proceedings of the Conference Road Safety on Four Continents, Varsaw, Poland, 2005.

20. Harwood, D.H., F.M. Council, E. Hauer, W.E. Hughes, and A. Vogt. Prediction of the Expected Safety Performances of the Rural Two-Lane Highways. Publication FHWARD-99-207. FHWA, U.S. Department of Transportation, 2000.

21. Hauer, E., and B. Persaud. Safety Analysis of Roadway Geometry and Ancillary Features. Transportation Association of Canada Research Record, Ottawa, Canada, 1997.

22. Hauer, E. Lane Width and Safety. www.roadsafetyresearch.com. Accessed November 21, 2005.

23. Migletz, J., Fish, J.K., and J.L. Graham. Roadway Delineation Practices Handbook. Report FHWA-SA-93-001, Washington, D.C., 1994.

24. Rose, E.R., and P.J. Carlson. Spacing Chevrons on Horizontal Curves. In Transportation Research Record: Journal of the Transportation Research Board, No. 1918, TRB, National Research Council, Washington, D.C., 2005, pp. 84-91.

25. Transportation Research Laboratory. Monitoring of Local Authority Safety Schemes (MOLASSES) Database. www.trl.co.uk/molasses. Accessed June 12, 2006.

26. Proctor, S., M. Belcher, and P. Cook. Practical Road Safety Auditing. Thomas Telford, London, UK, 2001.

27. Odgen, K. Safer Roads: a Guide to Road Safety Engineering. Avebury Technical, Cambridge, UK, 1996.

28. Miller, T.R. Benefit-cost analysis of lane marking. In Transportation Research Record, No. 1334, TRB, National Research Council, Washington, D.C., 1992, pp. 3845.

29. Elvik, R., and V. Truls. The Handbook of Road Safety Measures. Elsevier Science, Oxford, UK, 2004.

30. Agent, K. R., L. O’Connell, E. R. Green, D. Kreis, J. G. Pigman, N. Tollner, and E. Thompson. Developing of Methodologies for Identifying High Crash Locations and Prioritizing Safety Improvements. Research Report KTC-03-15/SPR250-02-1F, Lexington, Kentucky, 2003. 
31. Hassan, Y., S.M. Easa, and A.O. Abd El Halim. Analytical Model for Sight Distance Analysis on Three-Dimensional Highway Alignments. In Transportation Research Record, No. 1523, TRB, National Research Council, Washington, D.C., 1996, pp. 110.

32. Road Directorate Ministry of Transport Denmark. Signing and Marking of Substandard Horizontal Curves on Rural Roads. Report 163, Copenhagen, DK, 1999.

33. Shen, J., A. Rodriguez, and A. Gan. Development and Application of Crash Reduction Factors: State-of-the-Practice Review of State Departments of Transportation. In TRB $83^{\text {rd }}$ Annual Meeting Compendium of Papers, CD-ROM, TRB, National Research Council, Washington, D.C., 2004.

34. Lamm, R., A. Beck, T. Ruscher, T. Mailaender, S. Cafiso, G. La Cava, and W. Matthews. How to Make Two-Lane Rural Roads Safer. Scientific Background and Guide for Practical Application. WIT Press, Southampton, United Kingdom, 2006.

35. Italian Ministry of Infrastructures and Transports. Guidelines for the Design of Road Infrastructures: D.M. n. 6792, 5/11/2001. Rome, Italy, 2001.

36. AASHTO. Roadside Design Guide. Washington, D.C., 1996.

37. Hauer, E., J.C.N. Ng, and J. Lovell. Estimation of safety at signalized intersections. In Transportation Research Record, No. 1185, TRB, National Research Council, Washington, D.C., 1988, pp. 48-61.

38. Jovanis, P.P., and H. L. Chang. Modeling the relationship of accidents to miles traveled. In Transportation Research Record, No. 1068, TRB, National Research Council, Washington, D.C., 1986, pp. 42-51. 